\title{
PENGARUH PENYULUHAN GIZI TERHADAP PENGETAHUAN IBU TENTANG POLA MAKAN BALITA DI DESA SAMBIREJO KECAMATAN MANTINGAN KABUPATEN NGAWI
}

\section{Effect of Nutrition Extension on Mothers' Knowledge of Eating Patterns of Toddlers in Sambirejo Village, Mantingan Sub-district, Ngawi Regency}

\author{
Suci Arsita Sari ${ }^{1)}$, Widardo' ${ }^{2)}$, Erindra Budi Cahyanto ${ }^{3)}$ \\ ${ }^{1)}$ Pascasarjana Ilmu Kesehatan Masyarakat, Universitas Sebelas Maret. \\ ${ }^{2}$ Fakultas Kedokteran Universitas Sebelas Maret. \\ ${ }^{3)}$ Prodi D IV Bidan Pendidik, Fakultas Kedokteran, Universitas Sebelas Maret. \\ e-mail: suciarsita@gmail.com
}

\begin{abstract}
ABSTRAK
Latar Belakang: Status gizi menjadi salah satu indikator untuk menentukan derajat kesehatan anak. Pemberian gizi yang tidak tepat bagi balita dapat menyebabkan defisiensi nutrisi. Penyuluhan gizi menjadi salah satu upaya untuk meningkatkan pengetahuan ibu tentang pola makan balita. Penelitian ini bertujuan untuk mengetahui pengaruh penyuluhan gizi terhadap pengetahuan ibu tentang pola makan balita.

Metode: Jenis penelitian ini adalah penelitian kuantitatif yang menggunakan desain quasi experiment dengan control group pretest-posttest. Penelitian ini dilakukan di Desa Sambirejo, Mantingan, Ngawi pada awal bulan Mei 2016. Sampel dalam penelitian ini adalah ibu balita sejumlah 70 responden yang diambil dengan teknik cluster random sampling. Instrumen penelitian menggunakan kuesioner. Teknik analisis data menggunakan uji mann whitney.

Hasil: Penelitian ini menunjukkan bahwa rerata skor pre-test dan post-test pada kelompok perlakuan sebesar 47.9 dan 83.9. Rerata skor pre-test dan post-test pada kelompok kontrol sebesar 56.3 dan 56.5. Selisih rerata skor pre dan post-test kelompok perlakuan sebesar 36, lebih tinggi dibandingkan kelompok kontrol dengan selisih rerata sebesar 0.2.

Kesimpulan: Terdapat pengaruh penyuluhan gizi terhadap pengetahuan ibu tentang pola makan balita di Desa Sambirejo, Kecamatan Mantingan, Kabupaten Ngawi secara signifikan (nilai $\mathrm{p}=0.001$ ).
\end{abstract}

Kata kunci: Penyuluhan gizi, pengetahuan, ibu balita 


\section{ABSTRACT}

Background: Nutritional status becomes one of the indicators to determine the toddlers' health rate. The improve nutrition administration to the toddlers can cause nutritional deficiency (malnutrition). Nutrition extension is one the efforts to improve the mother's knowledge of eating patterns of toddlers. The objective of this research is to investigate the effect of nutrition extension on the mothers' knowledge of eating patterns of toddlers.

Method: This research used the quasi experimental quantitative method with the control group pretest-posttest design. It was conducted in Sambirejo Village, Mantingan Subdistrict, Ngawi Regency in the early May 2016. Its subjects were the mothers with toddlers as many as 70 respondents. They were determined through the cluster random sampling technique. The data of research were collected through questionnaire and analyzed by using the Mann Whitney's test.

Results: The pre-test and post-test scores of the experimental group were 47.9 and 83.9 respectively, and those of the control group were 56.3 and 56.5 respectively. The difference between the pre-test score and the post-test score of the experimental group was 36, the difference between the pre-test score and the post-test score of the control group = 0.2. The difference of the former was higher than that of the latter.

Conclusion: Nutrition extension has a significant effect on the mothers' knowledge of eating patterns of toddlers in Sambirejo Village, Mantingan Sub-district, Ngawi Regency (The $p$-value $=0.001$ ).

Keywords: Nutrition extension, knowledge, mothers with toddlers

\section{PENDAHULUAN}

Status gizi menjadi salah satu indikator untuk menentukan derajat kesehatan anak. Status gizi yang baik dapat membantu proses pertumbuhan dan perkembangan anak untuk mencapai kematangan yang optimal $^{[1]}$. Saat ini Indonesia sedang mengalami masalah gizi pada balita. Adapun masalah gizi yang di hadapi Indonesia adalah stunting atau tinggi badan menurut umur kurang, wasting atau berat badan menurut tinggi badan kurang, dan overweight atau berat badan menurut tinggi badan lebih. Pemerintah sudah berupaya menuntaskan masalah gizi tersebut dengan menggalakkan berbagai macam program. Namun, program yang telah dilakukan pemerintah ini belum efektif dalam penanggulangan masalah gizi tersebut, salah satu penyebabnya karena kurangnya pengetahuan ibu mengenai pola makan yang sehat dan gizi-gizi yang harus dipenuhi anak pada masa pertumbuhan.

Indonesia masuk dalam 17 negara yang mempunyai masalah gizi pada balita di antara 117 negara lainnya, yaitu stun- ting sebanyak 7.212.630 (37.2\%), wasting sebanyak 2.346 .043 (12.1\%), dan overweight sebanyak $2.307 .266(11.9 \%)$ dari 19.388.791 balita pada tahun 2014. Berdasarkan data profil kesehatan Indonesia tahun 2014 terdapat balita yang menderita stunting sebanyak 19\%, wasting sebanyak $7 \%$, dan overweight sebanyak $4.1 \%$ dari 2.419.795 balita di Jawa Timur. Berdasarkan data Dinas Kesehatan Kabupaten Ngawi terdapat 68 balita dengan gizi buruk dan sebanyak 420 balita dengan gizi kurang $^{[2]}$. Di desa Sambirejo terdapat 17 balita menderita gizi kurang dan 2 balita menderita gizi buruk dari 288 balita.

Berdasarkan studi pendahuluan yang dilakukan dengan wawancara terkait apa itu gizi seimbang, bagaimana kebutuhan gizi dan frekuensi makan balita di desa Sambirejo, terdapat 2 ibu balita yang sudah mengerti tentang pola makan pada balita dan ada 3 ibu balita yang kurang paham dan belum menerapkan pola makan yang benar untuk anaknya.

Gizi yang baik dan dikombinasikan dengan kebiasaan makan yang sehat sela- 
ma masa balita akan menjadi dasar bagi kesehatan yang bagus di masa yang akan datang. Pengaturan pola makan yang seimbang menjamin terpenuhinya kebutuhan gizi untuk energi dan pertumbuhan balita $^{[3]}$.

Perubahan pola sosial di berbagai daerah telah memberikan pengaruh kuat terhadap gizi balita. Tradisi untuk memasak di rumah atau menanam sayur sendiri telah bergeser menjadi belanja di supermarket hingga membeli atau memasak makanan cepat saji yang tidak terjamin nilai gizinya. Menurut Ikatan Dokter Anak Indonesia (IDAI), terdapat tiga faktor penyebab gizi buruk yaitu keluarga miskin, ketidaktahuan orang tua atas pemberian gizi yang baik bagi anak, dan faktor penyakit bawaan pada anak ${ }^{[4]}$.

Penanggulangan masa gizi perlu dilakukan secara terpadu antara departemen atau balai desa (Posyandu, Puskesmas, Rumah Sakit, dan lain-lain) dan kelompok profesi (bidan, perawat, dan dokter) melalui upaya-upaya peningkatan pangan, penganekaragaman produksi dan konsumsi pangan yang bertujuan untuk memperoleh perbaikan pola konsumsi (makan) masyarakat yang beraneka ragam dan seimbang dalam mutu gizi ${ }^{[5]}$. Selain melalui program-program pemerintah, solusi masalah tersebut sebaiknya didahului dengan upaya meningkatkan pengetahuan ibu melalui pendidikan kesehatan atau penyuluhan kepada masyarakat terkait upaya perbaikan gizi serta pemberian ASI pada bayi. Berdasarkan uraian di atas, peneliti tertarik untuk melakukan penelitian mengenai "Pengaruh Penyuluhan Gizi terhadap Pengetahuan Ibu tentang Pola Makan Balita di Desa Sambirejo, Kecamatan Mantingan, Kabupaten Ngawi““.

\section{SUBJEK DAN METODE}

Penelitian ini merupakan jenis penelitian kuantitatif yang menggunakan desain perlakuan semu (quasi experiment designs) dengan control group pretest-posttest. Perlakuan dalam penelitian ini dilakukan dengan memberikan penyuluhan gizi dengan teknik ceramah kepada ibu balita di Desa Sambirejo, Kecamatan Mantingan, Kabupaten Ngawi yang menjadi sampel penelitian. Kemudian diobservasi pengetahuan ibu balita sebelum intervensi dan sesudah intervensi.

Populasi dalam penelitian ini adalah seluruh ibu yang memiliki balita di Desa Sambirejo sebanyak 266 orang. Pengambilan sampel menggunakan teknik Cluster Random Sampling dan dihitung menggunakan rumus Lameshow dalam Riyanto ${ }^{(6)}$. Berdasarkan rumus tersebut, didapatkan sampel minimal 70 responden yang dibagi menjadi dua kelompok sehingga didapatkan 35 responden kelompok perlakuan dan 35 responden kelompok kontrol.

Intervensi yang dilakukan dalam penelitian ini adalah penyuluhan gizi tentang pola makan balita selama 60 menit. Menggunakan leaflet dan powerpoint sebagai media. Sebelum penyampaian materi dilakukan pre test untuk mengukur pengetahuan awal peserta. Penyuluhan gizi ini dilakukan dengan beberapa metode. Diawali dengan ceramah, yaitu pemaparan materi oleh peneliti, kemudian diskusi tanya jawab antara peserta, pemateri, dan bidan puskesmas. Setelah penyuluhan gizi selesai dilaksanakan, diakhir acara dilakukan evaluasi proses dengan cara memberikan pertanyaan kepada peserta dan meminta peserta untuk menyimpulkan materi penyuluhan yang disampaikan oleh peneliti. Post test dilakukan 1 minggu setelah penyuluhan gizi selesai.

Analisis data berupa analisis univariat dan analisis bivariat. Analisis bivariat dilakukan dengan uji Mann Whitney menggunakan SPSS 16 untuk mengetahui pengaruh penyuluhan gizi terhadap pengetahuan ibu tentang pola makan balita. 


\section{HASIL}

\section{Analisis Univariat}

Tabel 1. Karakteristik Responden

\begin{tabular}{|c|c|c|c|}
\hline \multirow[t]{2}{*}{ Karakteristik } & \multicolumn{2}{|c|}{ Frekuensi } & \multirow[t]{2}{*}{$(\%)$} \\
\hline & Perlakuan & Kontrol & \\
\hline \multicolumn{4}{|l|}{ Umur (tahun) } \\
\hline$<20$ & 4 & 2 & 8.57 \\
\hline $20-35$ & 29 & 32 & 87.14 \\
\hline$>35$ & 2 & 1 & 4.29 \\
\hline \multicolumn{4}{|l|}{ Jenis Pendidikan } \\
\hline Dasar (SD, SMP) & 3 & 3 & 8.57 \\
\hline Menengah (SMA) & 25 & 29 & 77.14 \\
\hline Perguruan Tinggi & 7 & 3 & 14.2 \\
\hline \multicolumn{4}{|l|}{ Jenis Pekerjaan } \\
\hline IRT & 18 & 15 & 47.14 \\
\hline Swasta & 8 & 10 & 25.71 \\
\hline Petani & 8 & 8 & 22.86 \\
\hline PNS & 1 & 2 & 4.29 \\
\hline \multicolumn{4}{|l|}{ Informasi } \\
\hline Pernah mendapatkan informasi & 32 & 34 & 94.29 \\
\hline Tidak pernah mendapatkan informasi & 3 & 1 & 5.71 \\
\hline
\end{tabular}

\section{Sumber data: Data Primer}

Berdasarkan tabel 1 diatas diketahui bahwa karakteristik responden penelitian pada kelompok perlakuan dan kontrol berdasarkan umur paling banyak berumur 20-35 tahun yaitu sebanyak 29 dan 32 responden. Karakteristik responden penelitian pada kelompok perlakuan dan kontrol berdasarkan jenis pendidikan paling banyak berpendidikan menengah (SMA) sebanyak 25 dan 29 responden. Karakteristik responden penelitian pada kelompok perlakuan dan kontrol berdasarkan jenis pekerjaan paling banyak adalah tidak bekerja atau sebagai IRT, yaitu sebanyak 18 dan 15 responden. Karakteristik responden penelitian pada kelompok perlakuan dan kontrol berdasarkan informasi yang pernah diperoleh paling banyak adalah pernah mendapatkan informasi, yaitu sebanyak 32 dan 34 responden.

\section{Analisis Bivariat}

Tabel 2. Pengetahuan tentang Pola Makan Balita Kelompok Perlakuan

\begin{tabular}{lccccc}
\hline & N & Rerata & SD & Terendah & Tertinggi \\
\hline Skor Pre-test & 35 & 47.9 & 15.7 & 26.7 & 96.7 \\
Skor Post-test & 35 & 83.9 & 4.6 & 70 & 93.3 \\
Selisih & & 36 & 16.2 & -10 & 60 \\
\hline Sumber data: Data Primer
\end{tabular}

Sumber data: Data Primer

Tabel 3. Pengetahuan tentang Pola Makan Balita Kelompok Kontrol

\begin{tabular}{lccccc}
\hline & $\mathrm{N}$ & Rerata & SD & Terendah & Tertinggi \\
\hline Skor Pre-test & 35 & 56.3 & 16.1 & 30 & 96.7 \\
Skor Post-test & 35 & 56.5 & 15.7 & 33.3 & 93.3 \\
Selisih & & 0.2 & 4 & -10 & 6.7 \\
\hline
\end{tabular}

Sumber data: Data Primer

Berdasarkan Tabel 5 diketahui bahwa rerata skor pre-test pada kelompok perlakuan sebesar 47.9. Rerata skor post-test se-

besar 83.9 dan selisih rerata sebesar 36. Berdasarkan Tabel 6 diketahui bahwa rerata skor pre-test pada kelompok kontrol 
sebesar 56.3. Rerata skor post-test sebesar 56.5. Selisih rerata 0.2.

\section{PEMBAHASAN}

Berdasarkan hasil penelitian diketahui bahwa rerata skor pre-test pada kelompok perlakuan sebesar 47.9. Rerata skor post-test sebesar 83.9. Selisih rerata sebesar 36. Rerata skor pre-test pada kelompok kontrol sebesar 56.3. Rerata skor post-test sebesar 56.5. Selisih rerata 0.2. Pengukuran pengetahuan dalam penelitian ini menggunakan kuesioner pengetahuan ibu balita tentang pola makan. Berisi 30 butir soal terdiri 5 indikator, yaitu pengertian pola makan, gizi seimbang, kebutuhan nutrisi balita, frekuensi makan, dan teknik mengolah makanan. Nilai terendah yang diperoleh responden terletak pada indikator gizi seimbang dan kebutuhan gizi balita.

Gizi seimbang pada balita mempunyai peranan penting dalam pola makan balita. Hal tersebut karena dalam prinsip gizi seimbang terdapat susunan pangan sehari-hari yang mengandung jenis dan jumlah yang sesuai dengan kebutuhan tubuh dalam rangka mempertahankan berat badan normal untuk mencegah terjadinya masalah gizi ${ }^{[2]}$. Pemberian makanan secara seimbang pada usia dini akan berpengaruh pada selera makan anak selanjutnya. Kebutuhan gizi balita akan terus bertambah seiring bertambahnya usia anak. Asupan gizi pada balita digunakan untuk proses pertumbuhan dan perkembangan. Namun, jika melebihi kebutuhan tubuh akan menyebabkan kelebihan berat badan dan penyakit lain yang disebabkan oleh kelebihan zat gizi. Sebaliknya, asupan gizi kurang dari yang dibutuhkan akan menyebabkan tubuh menjadi kurus dan rentan terhadap penyakit ${ }^{[12]}$.

Berdasarkan hasil uji statistik dengan Mann Whitney diketahui bahwa nilai $\mathrm{p}=0.001$ maka $\mathrm{H}_{0}$ ditolak dan $\mathrm{H}_{1}$ diterima. Artinya penyuluhan gizi berpengaruh terhadap pengetahuan ibu tentang pola makan balita secara signifikan karena nilai $p<0.05$. Hasil penelitian tersebut sesuai dengan teori Maulana ${ }^{[13]}$ bahwa penyuluhan merupakan suatu upaya untuk meningkatkan pengetahuan dan kesadaran, di samping sikap dan perilaku. Peningkatan pengetahuan kelompok perlakuan lebih tinggi daripada kelompok kontrol terjadi karena adanya perlakuan yang diberikan pada responden berupa penyuluhan. Prinsip pokok penyuluhan adalah proses belajar. Seseorang dikatakan belajar apabila terjadi perubahan dari tidak tahu menjadi tahu $^{[14]}$. Agar proses belajar berjalan dengan efektif dan efisien diperlukan metode, teknik, dan media yang sesuai ${ }^{[13]}$.

Penelitian ini menggunakan metode pemberdayaan masyarakat dengan teknik ceramah. Ceramah cocok digunakan untuk penyuluhan dalam kelompok dengan sasaran yang berpendidikan tinggi maupun rendah. Teknik ceramah yang dimaksud disini adalah ceramah dengan kombinasi teknik yang bervariasi. Ceramah dilakukan dengan tujuan sebagai pemicu terjadinya kegiatan yang partisipatif (curah pendapat, diskusi, studi kasus, dll). Selain itu, ceramah yang dimaksud disini adalah ceramah yang cenderung interaktif, yaitu melibatkan peserta melalui adanya tanggapan balik atau perbandingan dengan pendapat dan pengalaman peserta ${ }^{[14]}$.

Penelitian ini menggunakan media leaflet dan powerpoint saat penyuluhan. Media leaflet adalah media berbentuk selembar kertas yang berisi tulisan dan gambar. Leaflet dapat dilipat sehingga berukuran kecil dan praktis dibawa sehingga memudahkan peserta untuk belajar secara mandiri. Leaflet sangat efektif untuk menyampaikan materi karena berisi gagasan pokok materi yang dijelaskan secara ringkas dan lugas ${ }^{[15]}$. Powerpoint juga sangat efektif dalam penyampaian materi, karena slide dalam powerpoint dapat memperjelas materi. Dengan adanya slide powerpoint juga dapat menimbulkan semangat belajar dan interaksi antara peserta dan pemateri $^{[15]}$. Notoatmodjo ${ }^{[8]}$ menyatakan bahwa setelah mendapatkan stimulus berupa penyuluhan, dalam diri seseorang terjadi proses penerimaan pengetahuan yang 
berurutan. Dimulai dari awareness (kesadaran), di mana orang tersebut menyadari dalam arti mengetahui terlebih dahulu terhadap stimulus (objek). Dalam hal ini responden menyadari dan mengetahui adanya penyuluhan gizi yang berisi materi mengenai pola makan balita. Setelah itu interest (merasa tertarik), yaitu orang tersebut mulai tertarik terhadap stimulus atau objek tersebut. Disini sikap subjek sudah mulai timbul. Responden merasa tertarik untuk mengikuti penyuluhan dan antusias dalam mendengarkan materi yang disampaikan dalam penyuluhan. Lalu evaluation (menimbang-nimbang), dimana orang tersebut menimbang-nimbang terhadap baik dan tidaknya stimulus tersebut bagi dirinya. Hal ini berarti sikap responden sudah lebih baik lagi. Responden mulai dapat membedakan pola makan yang baik dan tidak baik untuk anak balitanya. Di tahap ini responden sudah mengetahui pola makan yang benar untuk balita.

Berdasarkan hasil penelitian diketahui bahwa terdapat 2 responden $(5.8 \%)$ dalam kelompok perlakuan yang mengalami penurunan pengetahuan. Hal itu terjadi karena pada saat penyuluhan atau penyampaian materi terdapat balita yang rewel, sehingga mengganggu konsentrasi responden dan peneliti dalam proses penyuluhan. Konsentrasi yang terganggu menyebabkan responden kesulitan dalam proses belajar dan penyerapan materi, sehingga mempengaruhi hasil belajar menjadi rendah dan tidak optimal ${ }^{[16]}$.

\section{SIMPULAN}

1. Pada kelompok perlakuan rerata nilai pre-test sebesar 47.9 dan post-test sebesar 83.9.

2. Pada kelompok kontrol rerata nilai pretest sebesar 56.3 dan post-test sebesar 56.5 .

3. Terdapat pengaruh penyuluhan gizi terhadap pengetahuan ibu tentang pola makan balita di Desa Sambirejo, Kecamatan Mantingan, Kabupaten Ngawi secara signifikan (nilai $P=$ $0.001)$

\section{SARAN}

1. Diharapkan ibu balita lebih memperhatikan pola makan anaknya dengan menu makanan yang bervariasi dan gizi seimbang. Selain itu, ibu balita diharuskan untuk lebih aktif dalam mencari informasi kesehatan khusunya mengenai gizi keluarga.

2. Diharapkan kepala puskesmas membuat program berupa penyuluhan gizi yang dilakukan secara berkala dan berkelanjutan.

3. Diharapkan bidan ataupun tenaga kesehatan lainnya mengembangkan dan meningkatkan kemampuannya dalam melakukan penyuluhan gizi kepada ibu balita.

4. Diharapkan institusi pendidikan untuk dapat mengadakan kegiatan pengabdian masyarakat yang dilakukan bersama mahasiswa secara berkala berupa penyuluhan gizi tentang pola makan balita.

5. Diharapkan hasil penelitian ini dapat dijadikan referensi untuk penelitian selanjutnya dan dapat mengembangkan penelitian ini.

\section{DAFTAR PUSTAKA}

1. Hidayat AAA (2008). Pengantar Ilmu Kesehatan Anak untuk Pendidikan Kebidanan. Jakarta : Salemba Medika, pp: $2-26$.

2. Depkes RI (2014). Pedoman Gizi Seimbang.

3. Thompson J (2003). Toddlercare : Pedoman Merawat Balita. Jakarta : Erlangga, pp: $61-5$.

4. Meadow R (2005). Pediatrika. Jakarta : Erlangga, pp: $81-8$.

5. Almatsier (2010). Prinsip Dasar Ilmu Gizi. Jakarta : Gramedia Pustaka Utama, pp: 311.

6. Riyanto A (2011). Aplikasi Metodologi Penelitian Kesehatan. Yogyakarta: Nuha Medika, pp: 10749.

7. Wawan, Dewi (2010). Teori dan Pengukuran Pengetahuan, Sikap, dan 
Perilaku Manusia. Yogyakarta : Nuha Medika, pp: $11-6$.

8. Notoatmodjo S (2010). Ilmu Perilaku Kesehatan. Jakarta : Rineka Cipta, pp:18 - 87.

9. Soekamto S (2004). Sosiologi Suatu Pengantar. Jakarta : Raja Grafindo Persada, pp: 37.

10. Azwar S (2003). Sikap Manusia.Yogyakarta : Pustaka Pelajar, pp: $25-30$.

11. Notoatmodjo S (2003). Pendidikan dan Perilaku Kesehatan. Jakarta : Rineka Cipta, pp: 27 - 144.
12. Sulistyoningsih (2011). Gizi Untuk Kesehatan Ibu dan Anak. Yogyakarta : Graha Ilmu, pp: $54-73$.

13. Maulana H (2009). Promosi Kesehatan. Jakarta : EGC, pp: 13 243.

14. Fitriani S (2011). Promosi Kesehatan. Yogyakarta : Graha Ilmu, pp: $42-55$.

15. Simamora R (2009). Buku Ajar Pendidikan dalam Keperawatan. Jakarta : EGC, pp : $66-70$.

16. Surya H (2009). Menjadi Manusia Pembelajar. Jakarta : Kelompok Gramedia, pp: 19. 